Journal of Engineering and Applied Sciences 14 (21): 7892-7898, 2019

ISSN: 1816-949X

(C) Medwell Journals, 2019

\title{
Development of Complaint Management System
}

\author{
Nur Izzati Binti Mohd Asri and Aruna Azariah Rajendram \\ Malaysian Institute of Information Technology, Universiti Kuala Lumpur, \\ 1016 Jalan Sultan Ismail, 50250 Kuala Lumpur, Malaysia, ezatyasri@gmail.com
}

\begin{abstract}
In order to make big leaps in delivering customer satisfaction, the organization does every possible aspect in maintaining the qualities of the services. As this is the online Era where everything is online we need to develop a system in online which is very useful to measure customer satisfaction where the issues of the customers can be registered online and resolved by the company. The purpose of this project is to greatly lighten the load on the company's end as the entire process of taking complaint is automated. With this, the company can access the customer dissatisfaction in a faster way, avoid data redundancy and remove the resources such as papers for data saving. To use the system, new user need to register in order to login. With the development of this research, the company can evaluate the issues and dissatisfaction found, check how the use of these systems may contribute to better performance of the administrative processes, improve management and allow for higher quality decision-making.
\end{abstract}

Key words: Feedback, dissatisfaction, complaint, management, performance, satisfaction

\section{INTRODUCTION}

In recent years, there has been increased interest in the topic of technology uses in employment workplace. Almost all organizations now a days in this world using technology such as internet in their department. Malaysia now a days encourages the employers to use Internet to gain more knowledge and information. Today in the industry, managements are at least taking a good step about creating positive and consistent customer experiences. Complaints management has become an integral part of business, both from a regulatory perspective and a customer service standpoint. Simply stated, complaints management is the formal process of recording and resolving a customer complaint. It means listening to dissatisfied customers and taking actions to remedy issues where appropriate.

A customer care tracking system is mainly designed for a company dealing with the distribution of chemical and cleaning supplies. It is one of the latest enhancement tools needed by an organization. An effective management is one of the crucial requirements for successful businesses when managing customer's needs and protecting their brand. This system is the platform where the customers can registered online their complaint and resolved by the company. It may be a 'best of breed' consumer feedback system or a module of a broader CRM system.
The system acts as a bridge between customer and company in which customer directly register their complaint to the company via. internet. A customer care tracking system is very user-friendly and easy to use. It also helps to measure customer satisfaction and one of the useful source of information and feedback for improving services.

\section{Main body}

Analysis of the current system: Identifying needs is important in the development of the system. It can be defined as the desire to identify a user in determining what needs to be developed in the system. Some specific methods and approaches used to obtain information suitable to be applied in the development of this system. People who are more used to the old systems are known as "Manual Written System", may find the new system uncomfortable to use in the beginning as it is something new that they have not used before.

Alternatively, from the firm as a learning organism perspective (Argyris and Schon, 1978), customer complaints present a valuable opportunity to gain strategic marketplace information on how to improve internal processes and focus managerial attention on specific problem areas. Understanding the root causes of customer problems and achieving complaint based improvements facilitate competitive success (Johnston, 2001). This rather critical role of customer complaints seems to have been largely overlooked in prior empirical

Corresponding Author: Nur Izzati Binti Mohd Asri, Malaysian Institute of Information Technology, Universiti Kuala Lumpur, 1016 Jalan Sultan Ismail, 50250 Kuala Lumpur, Malaysia, ezatyasri@gmail.com 
research and in the practice of complaint management. As Homburg and Furst (2005) state firmly, "many firms do not use the information inherent in complaints to facilitate systematic improvements".

Currently, manual system are used to monitor the complaints and feedback of the customer. The biggest disadvantage with manual records is simply that the organizations have to physically store them for so long. Most of the records were kept for 7 years or longer. A possibility of lost complaint records is very high because many documents are needed to be created to record the data. The biggest downfall to manual document filing is the amount of space it can take up. The company might find themselves taking up rooms just to fit the files in. This also means they have to go out of their way to hunt down a file of a client. It interrupts the company's productivity levels.

Another harsh reality is that files can be destroyed or stolen, for example, the company has flooded from a leaky sink not caught over the weekend, the company completely burned down in a fire or the computer and other equipment were stolen. These things really do happen and it's unfortunate to lose, so much, information, so, easily. They will have to start over at square one getting the information back. It can also lead them to losing clients who don't appreciate their mishandling of their information.

Other than that using manual records can be more time-consuming than using a computer to complete a work. Not only they have to organize and store the files, hunting down the information when it is need can take time. It can cause annoyance and this applies to both clients as well as the administration. In some ways, sharing documents can be easier with paper but it can also be more difficult, if they need to fax or scan things that would have otherwise already been uploaded electronically. Paper document filing can also be less secure than computerised filing systems. Misplaced documents can easily be placed in the wrong hands because clients expect their information to be secured. Human error, bad management and inefficiency are all problems that can be solved by using a computerized system.

Customer Relationship Management (CRM): Customer Relationship Management (CRM) is a combination of policies, processes and strategies implemented by an organization to unify its customer interactions and provide a means to track customer information. It involves the use of technology in attracting new and profitable customers while forming tighter bonds with existing ones. CRM also can be defined as marketing database emphasizing relationship network with customers by using various marketing tactics to seek customer retention (Bicket 1992; Vavra, 1992).

Kennedy defines customer relationship management as being "about identifying a companies best customers and maximizing the value from them by satisfying and retaining them". There are those who argue for and against CRM but the research remains consistent that a properly implemented, company-wide CRM initiative will truly save a company money, increase revenue and grow customer loyalty.

CRM needs a deep understanding of the customer expectations, attitude and behavior through a well-organized and maintained customer database and innovative customer strategies. The goal of CRM is to ensure customer satisfaction and delight at every level of interface with the company (Pahuja and Verma, 2008). Customer retention is a cost-effective way for an organization making a profit without seeking for new customers. They should build a strong and lasting relationship with current customers to strengthen the network for the mutual benefit of both sides. Berry stated that CRM is strategically concerned of the intermediate step in the marketing process is attracting new customers and following by loyalty program to develop a closer relationship with the customer.

Definition of database management system: A database is similar to a data warehouse involving the structure, storage and management of data. In the mid-1960's, computer storage emerged along with the development of computer storage equipment and software for data management was also introduced in this period. Database storage technology has been improving rapidly and the database storage speed and co-organization have been greatly enhancing for the benefit of a group of technical users.

A Database Management System (DBMS) also known as system software for creating and managing databases. The DBMS provides users and programmers with a systematic way to create, retrieve, update and manage data. A DBMS makes it possible for end users to create, read, update and delete data in a database. The DBMS essentially serves as an interface between the database and end users or application programs, ensuring that data is consistently organized and remains easily accessible.

Recently, the development and improvement of database technologies give several researchers chances to method learn to combine them with practical engineering. Whether the design of a database is successful or not is directly related to the construction of 
the engineering information system and its operating efficiency. It gives major effect on the engineering data information management, data storage time saving and project production efficiency improvement, so that, the database system is designed and developed accurately and reasonably.

The DBMS is perhaps most useful for providing a centralized view of data that can be accessed by multiple users, from multiple locations, in a controlled manner. A DBMS can limit what data the end user sees as well as how that end user can view the data, providing many views of a single database schema. End users and software programs are free from having to understand where the data is physically located or on what type of storage media it resides because the DBMS handles all requests.

DBMS lets end users and application programmers access and use the same data while managing data integrity. Data is better protected and maintained when it can be shared using a DBMS instead of creating new iterations of the same data stored in new files for every new application. The DBMS provides a central store of data that can be accessed by multiple users in a controlled manner.

\section{Central storage and management of data within the DBMS provides:}

- Data abstraction and independence

- Data security

- A locking mechanism for concurrent access

- An efficient handler to balance the needs of multiple applications using the same data

- The ability to swiftly recover from crashes and errors, including restorability and recoverability

- Robust data integrity capabilities

- Logging and auditing of activity

- Simple access using a standard Application Programming Interface (API)

- Uniform administration procedures for data

When a DBMS is used, systems can be modified much more easily when business requirements change. New categories of data can be added to the database without disrupting the existing system and applications can be insulated from how data is structured and stored.

Customer behaviour in complaining dissatisfactions: Customers become dissatisfied when product or service performances are not up to their expectations. Understanding the potential sources of dissatisfaction and customer's reactions to negative situations are mandatory requirements in the design of effective service recovery strategies. Customer responses to various errors or unpleasant incidents are not unique (Voinea, 2011). Some individuals will initiate a public action which may consist of such as sending a complaint to the organization, complaining to a third party such as to a consumer association or even trying to solve the problem through a legal action.

Thus, electronic communication channels enable customers who experience high levels of dissatisfaction to talk about their consumption experience with a large number of people. Research on customer dissatisfaction has shown that only a small percentage of customers that had negative consumption experiences have submitted their complaints to the organizations. Some examples are given by the following facts for every complained received by a company, there are nineteen other dissatisfied customers who did not make the effort to complain. Of the total number of customers that felt dissatisfied with a particular product or service, only between 5 and 10\% made claims and in some cases the percentage is even lower (Tax et al., 1998).

Customers who make complaints are providing an organization with the opportunity to solve certain operational malfunctions, to learn from negative situations and consequently to re-establish their satisfaction and trust. Customer satisfaction with the complaint management process is influenced by the concept of justice, highlighting customer's reactions to conflict contexts (Gilliland, 1993). In relationship marketing literature, justice is analysed as a three-dimensional concept, including distributive, procedural and interactional justice (Tax et al.,1998).

Complaint procedures should be flexible, easy to access and manage and must be concluded in a convenient and timely manner (Tax et al., 1998). Customers have a negative perception in a situation when they have to fill out difficult complaint forms, to send letters or to provide bureaucratic evidence about the product purchased. The use of such procedures does not send positive messages to customers about the management intentions to solve the difficulties occurred.

Thus, at the same time, customers want to see that real efforts are made to solve the problems and to eliminate the inconveniences. In this respect, employee's must display courtesy, honesty, empathy and ethical behaviour during the communications process with dissatisfied customers, aiming to re-establish organizational credibility and avoid image damage (Constantinescu, 2011).

Importance designing the recovery strategy: Complaint management is the process of dissemination of 
information aimed at identifying and correcting various causes of customer dissatisfaction (Fornell and Westbrook, 1984). It defines strategies used by companies to solve and learn from the previous mistakes in order to restore customer confidence in organizational reliability (Hart et al., 1990). Therefore, information gathered from customer complaints is of great significance for the quality management process as it can be used to correct and learn about weaknesses in product quality and delivery system.

Complaint handling involves the strategies used by companies to solve and learn from product and service failures in order to strengthen the organization's reliability in the eyes of the customer (Hart et al., 1990). Consequently, the development of an effective complaint management process must take into account customer expectations and justice dimensions in order to achieve higher levels of customer satisfaction and avoid switching behaviour.

An effective recovery strategy involves carrying out planned activities which can be summarized in three major steps: stimulate and receive complaints, resolve complaints and send feedback to the customer (Bateson and Hoffman, 1999). Actively encourage customers to express dissatisfaction is a necessary task for organizations, if we take into account the reluctance of customers to make complaints (Maxham and Netemeyer, 2002). Therefore, a good way to stimulate complaints is to identify which are customer reasons for not sending a feedback to the organization and then solutions can be sought to decrease or remove these obstacles.

According to Lovelock and Wirtz (2004), the barriers perceived by customers to express dissatisfaction are related to customer inconvenience with complaining procedures, consumption of time and energy to complain, the lack of customer confidence in the actions performed by organizations to remedy the problems or to address the causes of dissatisfaction, the customer fear of being treated in a rude manner, to be scolded or to feel embarrassed in discussions with employee's. Another barrier that may occur is the customer uncertainty about their own ability to evaluate the quality of products and services.

Organizations should have developed various procedures to receive customer complaints. The most common involve the use of free telephone lines, physical forms found in the place of consumption, links on organizational websites and information obtained from qualitative and quantitative marketing researchers (Bateson and Hoffman, 1999). Once the company received customer claims, the complaint resolutions process begins. This process involves setting procedures to clarify what actions will be performed by employee's in negative situations or bad customer experiences (Kelly et al., 1993).

Furthermore, the key to customer loyalty is customer satisfaction which largely depends on the service quality offered by service providing firms (Rahman, 2014). Trust is beneficial to forming and maintaining customer loyalty (Reichheld et al., 2000). The ability of the customers to take care of themselves through online or the company being able to take care of its customers through internet outlines can increase customer satisfaction.

Benefits of CRM adoption in the system: Now a days, people want life to be more convenience. They want to get things done in faster way yet get a quality output. There is where Information Technology (IT) comes in to help people and make their life easier. Instead of using a traditional manual way to perform tasks and disseminate information, people tend to make it automate because it will be more time effective yet remain quality.

Technology development is seen as a solution, allowing organizations or companies to enhance their service portfolios using latest technological advancements. Also, new technology development triggers the service development process to be more customer intensive with customized service offerings. With the shorter maturity times of different services and hence the service organizations, it became evident for businesses to pursue the technology development and its implementation aspects at a faster pace. It is established that technology plays an inevitable role in the service development process.

Ab Hamid and Kassim (2004) determine customer loyalty while partially impacted by the internet, also is determined by a combination of online experience with things such as the quality of after-sales service. Furthermore, Ab Hamid and Kassim (2004) found that the internet is currently most being used by companies "primarily for providing corporate information in order to build brand identity". Therefore, they are "providing corporate information rather than using the internet for other strategic purposes" (Ab Hamid and Kassim, 2004). This research supports the claim that there is still ample room for companies to embrace broader CRM initiatives including a more customer focused and useful online presence.

Customer retention is becoming very flexible. Customers switch to products and services offered by other organizations when they are dissatisfied. Organizations should offer high-quality products and services with a competitive price in order to promote customer loyalty. Customer relationship management can be a useful mechanism to render the customers loyal. 
Oliver (1999) defined loyalty as the inherent tendency and commitment to product or service (commitment) and not to change behaviours affected by the external environment and marketing activities.

\section{MATERIALS AND METHODS}

\section{Review of agile methodology}

Analysis: It involves identifying the objectives and scope that can be achieved of the project. In this phase, the researcher will collect the requirements with an interaction of client and collected requirements will be documented. The aim is to detect all the problems and needs of client. The researcher will consider if any constraints that may hinder the development process, such as client's time and budget constraints.

Design: The researcher is responsible to discuss the design, architecture and function of the system with the client in order to fulfil the client requirements. The researcher will create the system design by review the scope to ensure the design meet the objective and have functional requirement of the system. It also involves the creation of mock-ups or hand-drawn sketches, based upon the vision document and gathered requirements.

Development: In this phase, the researcher will code the program using suitable programming languages such as HTML and PHP or scripting languages in order to develop the system.

Implementation: Once the product is developed, it should undergo a meticulous quality assurance and software testing. It involves identifying, isolating and fixing the problems or bug that encounter an error in the code. The client should be involved in the testing and try using it exactly the way it will be used when implemented.

Evaluation: When the system is tested and deployed at the client's server, generally, the client may come up with functionality enhancements to the developed software and researchers will have to collect, describe and discuss the new requirements with the client to have these modifications made. The code modified repeatedly until the client satisfied with the system. Once the major code problems are fixed, the software can be deployed.

\section{RESULTS AND DISCUSSION}

Testing: The system tested in various ways such as by observing user experiences on 25 April 2018 by asking question of users by timing the flow through specific usage scenarios and by comparing it with other sites. To meet the objectives of developing the customer care tracking system for this company, usability testing was conducted.

Usability testing: Usability testing refers to evaluating a product or service by testing it with representative users. Usability testing is the best way to understand how real users experience the system or application. Typically, during a test, participants will try to complete typical tasks while observers watch, listen and takes notes. The goal is to identify any usability problems, collect qualitative and quantitative data and determine the participant's satisfaction with the product.

A usability test makes sure that the interface of the system is built in a way that fits the user's expectations with respect to meeting requirements (effectiveness) easily (efficiently) in a simplistic satisfying manner. The primary focus is on:

- $\quad$ Ease of use

- Ease of learning or familiarizing with the system

- Satisfaction of the user with the entire experience

\section{Testing process}

Usability test session: The test was conducted where each respondent will be given a questionnaire to be answered based on the system (Fig. 1). The 40 people had been selected to test the prototype and answer the questionnaire. The testing protocol as follows:

- The researcher welcome the participant, explain the test session and ask the participant to fill in the form

- The researcher asks, if the participant has any additional questions. The researcher explains where to start

- The participant reads the questions and begins working on the system

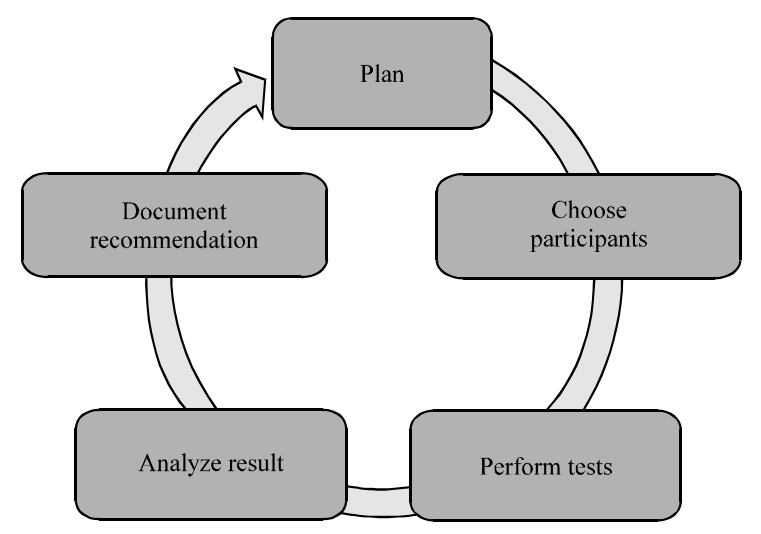

Fig. 1: Testing process 


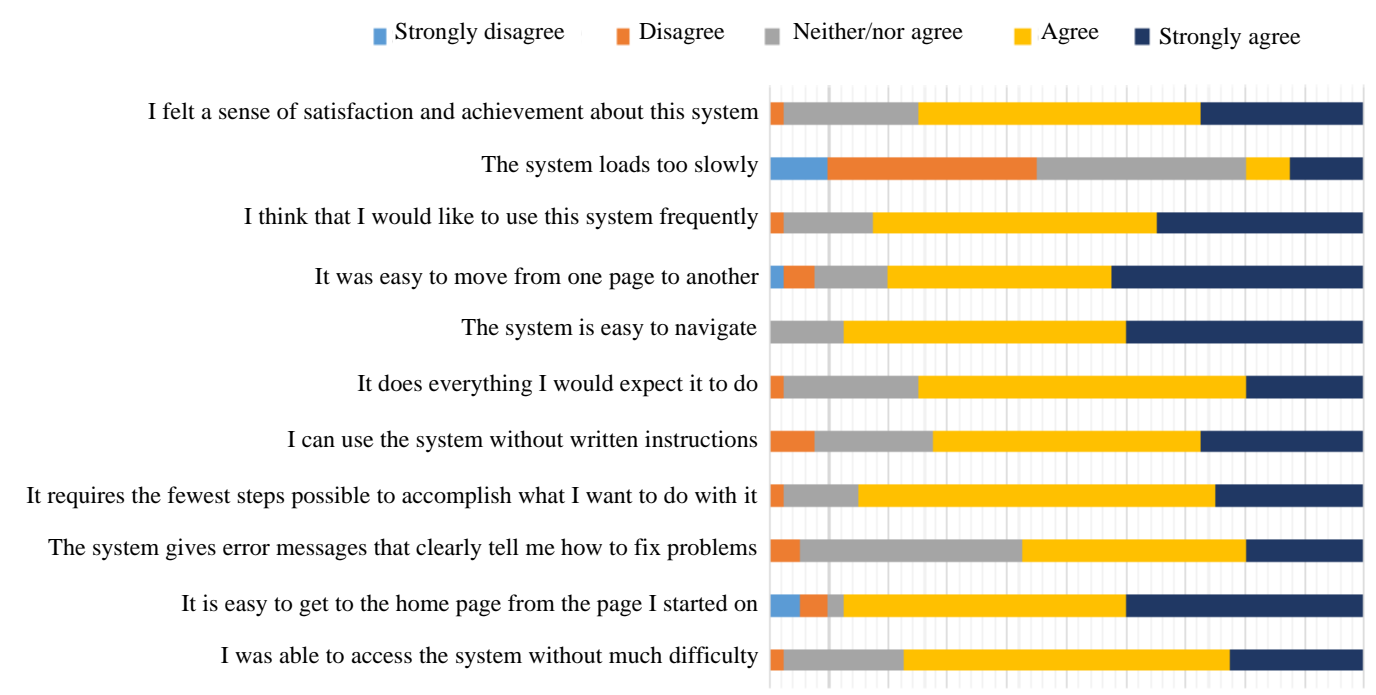

Fig. 2: Group of questionnaire

- The researcher takes notes of the participant's comments, errors and completion (success or failure) on each task

- The session continues until all task scenarios are completed or time allotted has elapsed

- The researcher thanks the participant, gives the participant the agreed-on incentive and escorts them from the testing environment

Analysis of each group of questionnaire: Testing will point out the errors that occur during the development phases. It makes sure that the application's performances are adequate and that customers are satisfied with it. When the delivered product is of quality, it helps in gaining the confidence of the customers. This is essential to the success of the overall effort and delivering a quality system to end user (Fig. 2).

\section{CONCLUSION}

In developing the customer care tracking system, the developer learned how to cope up with the stress of working and the ever-changing environment of encountering with many problems that hinder the project to be completed. The accomplishment considers some factor such as whether the objective of the project has been reached that have been identified. The system is designed to works on web-based and it contains two sub users which are the administrator and the user (customers of the company). The administrator controls the complete system. Functions available to user includes user registration, reset password, lodge any complaint occur, view complaint history and give feedback. All new user are required to register in order to use the system.
This customer care tracking system is built to be effective and efficient in data management. It is very suitable to be implemented as it enables Admin to manage the complaint anytime and anywhere. Furthermore with this system, it can help the organization to improve their business process and reduce the workload, hence, saving time and reducing the likelihood of errors compared with running them manually.

\section{RECOMMENDATIONS}

The completed project has been verified as working and functioning well. However, there are still some parts that need to be revised and some function could be added to enhance the system. All are based on reflection about what has worked to date and what next steps must be taken to advance the building of the system. As for the future improvement, the developer anticipates that:

- The system could be upgraded to a mobile application

- The system could be integrated with Short Messaging Service (SMS) to notify users

- The system could be modified to work with smart reference system, to allow user to use it for authentications purpose

\section{REFERENCES}

Ab Hamid, N.R. and N. Kassim, 2004. Internet technology as a tool in customer relationship management. J. Am. Acad. Bus., 4: 103-108. 
Argyris, C. and D.A. Schon, 1978. Organizational Learning: A Theory of Action Perspective. Addison-Wesley, Boston, Massachusetts, USA., ISBN:9780201001747, Pages: 344.

Bateson, J.E.G. and K.D. Hoffman, 1999. Managing Services Marketing: Text and Readings. 4th Edn., Dryden Press, Fort Worth, Sydney, ISBN: 0030225191, Pages: 471.

Bicket, J., 1992. The database revolution. Target Marketing, 15: 14-22.

Constantinescu, M., 2011. The relationship between quality of life and marketing ethics. Rom. J. Marketing, 6: 41-44.

Fornell, C. and R.A. Westbrook, 1984. The vicious circle of consumer complaints. J. Marketing, 48: 68-78.

Gilliland, S.W., 1993. The perceived fairness of selection systems: An organizational justice perspective. Acad. Manage. Rev., 18: 694-734.

Hart, C.W.L., J.L. Heskett and E.W. Sasser Jr., 1990. The profitable art of service recovery. Harvard Bus. Rev., 68: 148-156.

Homburg, C. and A. Furst, 2005. How organizational complaint handling drives customer loyalty: An analysis of the mechanistic and the organic approach. J. Market., 60: 95-114.

Johnston, R., 2001. Linking complaint management to profit. Intl. J. Serv. Ind. Manage., 12: 60-69.

Kelly, S.W., K.D. Hoffman and M.A. Davis, 1993. A typology of retail failures and recoveries. J. Retail., 69: 429-452.
Lovelock, C. and J. Wirtz, 2004. Services Marketing: People, Technology and Strategy. 5th Edn., Pearson Prentice Hall, New Jersey.

Maxham, J.G. and R.G. Netemeyer, 2002. A longitudinal study of complaining customer's evaluations of multiple service failures and recovery efforts. J. Market., 66: 57-71.

Oliver, R.L., 1999. Whence consumer loyalty?. J. Marketing, 63: 33-44.

Pahuja, A. and R. Verma, 2008. Customer relationship management: The need of the hour. Marketing Mastermind, 6: 67-73.

Rahman, D., 2014. The power of communication. Am. Econ. Rev., 104: 3737-3751.

Reichheld, F.F., G. Robert Jr and C. Hopton, 2000. The loyalty effect-the relationship between loyalty and profits. Eur. Bus. J., 12: 134-139.

Tax, S.S., S.W. Brown and M. Chandrashekaran, 1998. Customer evaluations of service complaint experiences: Implications for relationship marketing. J. Market., 62: 60-76.

Vavra, T.G., 1992. Aftermarketing: How to Keep Customers for Life through Relationship Marketing. 4th Edn., Business One Irwin, Homewood, Illinois, ISBN:9781556236051, Pages: 292.

Voinea, L., 2011. Mutations in new consumer buying behaviour. Qual. Access Success, 12: 47-51. 